\title{
Seeing farmers for the trees: community forestry and the arborealisation of agriculture in northern Thailand ${ }^{1}$
}

\author{
Andrew Walker \\ The Australian National University \\ andrew.walker@anu.edu.au
}

\section{Introduction}

For the villagers, where they live and find food is the same place - the forest. (Pirmsak quoted in Pennapa, 2002)

Forests have traditionally been the main source of sustenance for rural people. Without forests, rural people's livelihoods have been destroyed and they have been forced to migrate to urban areas, leading to family and community disintegration. (Prawase, 1997: 7)

This paper is motivated by my concern about the extent to which discussion of rural politics, rural development and resource management in upland areas of Southeast Asia are framed by the discourse of forests, obscuring the fact that most rural peoples' resource interactions are predominantly with agricultural lands and, increasingly, urban areas. It has become disconcertingly natural to speak and write in terms of "forest dwellers", "forest lives", and "forest struggles" (Doornbos et al., 2000) based largely on the premise that the proximity of forests to upland communities amounts to livelihood salience. And, in the now ubiquitous discussions of agro-forestry it is the forest half of the equation that carries normative weight, and the ecologically innovative promise of donor support. This recasting of upland livelihoods as forest livelihoods - a process I refer to as arborealisation - has tended to divert attention away from key livelihood issues posed by the current phase of upland commodity production and has spawned an array of proposals for "bottom up" resource regulation that appear inconsistent with the realities of household-based productive activity.

In this paper my specific objective is to critically examine the process of arborealisation in northern Thailand, focussing on the longstanding campaign for community forest legislation. While I acknowledge the significant political achievements of this campaign I suggest there is room for a more critical examination of the implications of the proposed legislation - and the forms of community-based resource management it advocates - for the management of agricultural land. I have no intention of denying that there are important points of linkage between forests and agricultural systems - both in the form of direct livelihood activities and also more indirect "environmental services"-however I do argue that these points of linkage are often ill-defined, and exaggerated, and do not necessarily justify the widespread elevation of forest management to a "first order" livelihood issue. Indeed the arboreal perspective that prevails in the proposed community forest legislation means that there is no explicit recognition of the legitimate role of agriculture in upland forested areas, despite the central philosophical claim that people and forests can coexist. To the extent that there is implicit recognition of agricultural activity it is brought within

\footnotetext{
${ }^{1}$ Thanks to Nicholas Tapp, Andrew McWilliam, Kuntala Lahiri-Dutt and colleagues in Chiang Mai for useful critique, comments and suggestions.
} 
a framework of communal land management that raises important problematic issues in relation to current tenure practices and aspirations.

\section{Arborealisation of agriculture in northern Thailand}

A key dynamic in the process of arborealisation in northern Thailand has been the highly politicised interaction between official and alternative perspectives on upland resource management. State policy in Thailand has long denied the legitimate presence of farmers in upland forested areas. For much of the twentieth century the state was actively involved in issuing logging concessions to both foreign and domestic firms, ignoring the role of local communities in the management of these resources. With the late-twentieth century shift in emphasis to conservation, state action has imposed various categories of forest protection on local agriculturalists in line with the objective of classifying one quarter of the country's area as conservation forest. This "grossly unrealistic" (Ammar et al., 1991: 12) administrative action has generated a massive mismatch between official land classification and actual landuse, creating the "ambiguous lands" referred to by Sato (2000) in which agricultural activities are rendered illegal. The impact of this administrative denial of local resource-use realities is particularly intense in the north where, in 1990, one third of villages were found to be located inside forest reserves (Sopin et al., 1990: 11). Farmers living in these areas have uncertain rights over their land and many lack formal tenure documents. Livelihood insecurity is compounded by persistent state plans - and occasional action - to relocate upland villagers to less environmentally sensitive midland and lowland locations. As the then chief of the Royal Forest Department stated in 1998 in response to claims for upland residency: "The forest exists for hundreds of years but you are just born...Y You can live in the forest if you live like barbarians. But now your life is civilised and we have no more forest left, so you have to go." (Chakrit, 1998, my emphasis.)

The response to state denial of the role of upland communities in local resource management has been appropriately vigorous. The key element in this campaign has been to assert that upland residents have a legitimate place within forested ecosystems because they have longstanding traditions of sustainable forest management. It is argued that the practical and symbolic aspects of these management systems need to be recognised as a legitimate component of the upland ecosystem. As an alternative to the Western-influenced state approach — which separates forests from people - a holistic counter-discourse is proposed in which various forms of forest, wildlife, water resources, agricultural fields and settlements coexist:

No one thing has more importance than another, and all are linked together so tightly that it is difficult to separate them. The forest survives because people help protect and regenerate it. The animals live because the forest is fertile... The streams have water because of the forest... The agricultural fields are fertile because the forest is fertile, it helps cover and protect the soil from being washed away. The water from the stream helps support the vegetation and the agricultural fields. There are many birds that help control insects and finally, people can live. This is because they have a fertile forest, clean, clear water, fertile land and wild animals. (NDF, 1999: 108-109) 
The overall thrust of this strategy has been to emphasise the intimacy of human livelihoods and forests in upland areas. Rather than merely arguing for the possibility of forest and agricultural coexistence, campaigners for the rights of upland communities have come to argue that upland forest and upland agriculture is intrinsically linked in inseparable relations of interdependency and that the relationship is underpinned by locally specific belief systems, cultural practices and forms of social organization (for a good example see Ekawit, 2001: 140-144). The effect of this has been that upland agriculture has come to be descriptively and normatively framed in terms of its role as a component of the broader forested ecosystem. This process, which I call arborealisation, has a number of key elements: a normative emphasis on an otherworldly orientation and subsistence production; an ongoing focus on shifting cultivation; an emphasis on the livelihood importance of forest production collection; and regular statements about the hydrological linkages between forests and agricultural systems. I discuss each of these issues in turn before turning to a detailed examination of the implications of this arboreal perspective as embodied in the proposed community forest legislation.

\section{Non-commercial orientation}

In the alternative discourse put forward by NGOs and activist academics the archetypal forest community is one in which production is overwhelmingly subsistence oriented. "Mae Khong Saay is a forest community" one report notes, "that is oriented to the simple life. The powerful and rapid current of development has not yet reached it. The system of production is just for meeting basic needs" (NDF, 1999: $78,84)$. This non-intensive focus on local needs is seen as underlying a "balanced" relationship between upland communities and the forest ecosystem. This balance is said to have a number of elements: demand for agricultural land is modest given the limited subsistence requirements of local households; fertiliser, chemical and pesticide use is minimal given that local rice strains are well adapted to the microenvironments of the uplands; and, instead of commercially oriented mono-cropping, mixed plantings in agricultural fields mimic and complement the biodiversity of the forest itself. At a socio-cultural level, the absence of market-oriented values, such as maximisation and competition, contributes to the maintenance of traditional values of respect for the natural environment (Nithi, 2001).

Of course the widespread reality of upland commercialisation is acknowledged, however this is framed as the product of external pressure on the authentic forestdwelling community. Both the market and the state are presented as intrusive nonlocal forces that disrupt the upland balance between forest and agriculture: market oriented cultivation of cash crops leads to forest clearing; state-sponsored development programs aimed at intensification and commodity production encourage adoption of modern chemical technologies that compromise watershed functions; and commercialisation leads to individualism, with communally-oriented beliefs and rituals of forest protection rapidly abandoned. With the forest no long providing a "sanctuary from the trials of day to day life ... people seek refuge in drugs and alcohol" (Prawase, 1997: 8). The overall effect of this anti-commercial discourse is a process of normative arborealisation, whereby desirable and appropriate upland agriculture equates with forest-friendly agriculture. Livelihood solutions come to be assessed in terms of their ability to facilitate a return to the basic values and practices of a subsistence-oriented engagement with predominantly forested ecosystems. 


\section{Shifting cultivation}

In the alternative discourse of human-forest relations, upland shifting cultivation features prominently. Usually this takes the form of a response to the unjustified charges levelled by forest administrators and regulators that shifting cultivation has been a primary cause of deforestation and provides a clear illustration of the inappropriateness of human presence in conservation areas. The argument that has been cogently put by activist academics and NGOs is that certain forms of shifting cultivation typify the balance between upland agriculture and forest ecosystems. Short-term cultivation combined with long-term fallow is said to create a "multilayered" forest in which fallow patches of varying age provide for a level of vegetative and faunal diversity that may even exceed that of primary forest (Kannika and Bencha, 1999). Sites appropriate for clearing and cultivation are carefully chosen - with choices informed by an array of ecological precepts-and forest regeneration on fallow land is facilitated by minimal soil disturbance, maintenance of tree stumps and preservation of ridge-top and streamline tree cover. For some upland groups, the Karen in particular, this form of forest-friendly cultivation has been promoted as lying at the heart of socio-cultural identify and economic pursuit (Walker, 2001).

The emphasis on shifting cultivation in much of the activist literature has played an important role in defending the residency rights of some of the most marginal upland groups (Pinkaew, 1999b). But, at the same time, it has generated a somewhat unbalanced view of upland agriculture that tends to ignore the considerable evidence that shifting cultivation has been all but abandoned in most upland areas of northern Thailand. Even where it persists fallows are significantly reduced and trends towards more intensive permanent cultivation are clear (Hansen, 2001; Kanok and Benjavan, 1994 ). This decline - which is evident throughout mainland Southeast Asia-owes something to the imposition of state forest conservation policies but the more fundamental underlying cause is substantial and sustained population growth in upland areas and widespread farmer preferences for more land-productive forms of cultivation (Walker, 2001). The ongoing defence and advocacy of shifting cultivation - while appropriate in some "niche advocacy" situations - is increasingly disconnected from an upland environment generally characterised by population growth, agricultural intensification and commodity production. And the effect of this emphasis on shifting cultivation is, again, to frame upland agriculture in arboreal terms, with primary attention given to the nature of the relationship between farmers and the forest rather on the economic, agronomic and demographic processes prompting widespread adoption of permanent cultivation.

\section{Forest product collection}

A third key element of the process of arborealisation is the emphasis on forest product collection and consumption. The impression given in much of the literature is that forest products play a crucial role in local subsistence economies and various authors have gone to considerable lengths to document extensive local wisdom about the management and use of medicinal herbs, mushrooms, roots, flowers and bark. Collection of forest products is said to be framed and regulated by an array of cultural precepts that ensure the sustainability of the forest ecosystem and considerable 
normative weight is placed on subsistence use rather than commercial exploitation of timber and non-timber resources.

As with shifting cultivation, the discussion of forest product collection and use tends to be couched in the predominantly cultural terms of holistic relationship between people and forests and there is usually a lack of specific information on the extent and significance of these activities in local economies (Olsen et al., 2001; Warner, 2000). Household surveying undertaken by myself and colleagues in the heavily forested Mae Chaem district suggest that forest products contribute consistently less than 10 per cent to household subsistence and cash incomes (and in some sub-districts as low as two per cent). Some corroboration of this general finding is provided by another study in one of the surveyed sub-districts in which only 14 percent of farmers nominated gathering of wild products as an adaptive strategy when faced with rice deficit problems (in contrast to the 87 percent that nominated wage labour)(Phrek et al., 1994: Table 1). Sato's (2000) study of Karen villages in Thung Yai Naresuan Wildlife Reserve in western Thailand provides a more rigorous and detailed analysis, and probably illustrates the higher range of forest product use. He found that poorer farmers derive around 35 percent of their income from forest products, predominantly the collection and sale of bamboo shoots. However it should be noted that this percentage refers only to cash income whereas the data cited above from Mae Chaem refers to the forest product percentage of both cash and subsistence income. If an estimated value of subsistence consumption of rice is taken into consideration in relation to Sato's data, income from bamboo shoots in the poorer group of households amounts to between 9 and 18 percent of their combined income. The percentage would be even lower if off-farm income was taken into consideration. Overall, the data does not support Sato's rather arborealised conclusion that "for many, especially the poor, the forest remains their only source of livelihood" especially given his own statement that "regardless of wealth and market access, most of the villager's meals are composed of ... rice, chilli, and some vegetables" (Sato, 2000: 170, my emphasis).

\section{Environmental services from forest}

Apart from "direct" livelihood services (such as forest product collection) forests are also said to provide important "indirect" environmental services to upland agriculturalists. Most generally this is often expressed in terms of the "holistic" view, noted above, that sees upland agriculture as an integral part of the broader forested ecosystem. In more specific terms, when asserting the intimate relationship between agriculture and forests, it is widely argued that forests play a key role in ensuring water supply for agricultural irrigation. Watershed forest protection by northern Thai irrigation groups is said to be one of the key antecedents of the modern community forestry movement and is widely reported to be a key component of contemporary community forestry activities (Anan, 1999: 35; Apinyaa, 2001: 34-40; NDF, 2000b; RFD, 1998: 23-28). Various forest-oriented ritual activities which "pay respect to the spirit of the headwater" have been "resurrected" (Chusak, 1999: 11) to add strength to the conservationist claim that upland agriculture is dependant on longstanding traditions of watershed management.

In other papers I have discussed the hydrological role of upland forests in considerable detail (Walker, 2002, 2003). Here I will only note that there is very little hydrological evidence supporting the claim that forests help secure downstream water 
supplies and good evidence that water shortages attributed to forest clearing are caused, in fact, by very significant increases in demand for water. Moreover, while general beliefs about the watershed functions of forests are often attributed to upland farmers there has been no sustained research on the specifics of indigenous hydrological knowledge in the region. There is a strong sense in much of the material on local hydrological knowledge that it has been selectively packaged to accord with the prevailing orthodoxy about the links between forest cover and agricultural water supply. Indeed, views such as those reported by Forsyth (1999: 13) - where upland farmers in Chiang Rai claimed that removal of tree cover was the key to securing good water supply - receive very little coverage in the arborealised accounts of the intimate relationship between forest and irrigated agriculture.

\section{Community forestry in northern Thailand}

Community forestry has become a central element in campaigns for the rights of upland farmers in northern Thailand and various activist organizations have placed legal recognition of community forest rights at the top of their political agenda. Proposed community forest legislation is presented as a much-needed response to coercive state policies that have excluded local people from the management of forest resources, undermined local traditions of sustainable resource management and fostered unsustainable resource competition and conflict. The campaign for community forest reform amounts to an explicit rejection of official claims that conservation and settlement are incompatible and asserts that "customary practice rooted in local culture" (Hirsch, 1997: 15) can provide a basis for sustainable livelihood in forested upland areas. In making this assertion, community forestry in northern Thailand strategically promotes a particular version of upland livelihood in which the arborealised perspective of agriculture discussed above justifies the claim that reform of forest management is essential for acknowledging the rights and improving the livelihoods of upland farmers.

For some time the community forest debate has been complicated by the preparation of a number of alternative drafts of proposed community forest legislation, with clear differences between the draft prepared by the Royal Forest Department and that prepared by an alliance of academics and NGOs (commonly referred to as the "people's version"). In early 2002 the House of Representatives passed a version of the bill that was broadly consistent with the people's version, however the Senate rejected key provisions and, at present, the bill appears to be in legislative limbo. In the following sections I will refer mainly to the people's version, as this is, no doubt, the most representative of the broader community forest movement.

The key provisions of the people's version are:

- A national level community forest policy committee will be established to set overall policy directions in relation to community forest administration and management (Article 8).

- A community forest committee will be established in each province. These provincial committees will be responsible for: receiving applications for the establishment of community forests; inspecting the proposed community forest 
areas; considering any objections from interested parties; approving the establishment of community forests; setting management conditions; and monitoring community forest performance.

- Representatives of local communities (at least 10 representatives who have the support of at least half the community) can propose the establishment of community forests provided they are in a position to take care of the forest (Articles 4 and 20). ${ }^{2}$ In forest conservation areas, such as national parks, applicants must demonstrate that they have been caring for the forest for at least five years prior to commencement of the Act and can demonstrate a "culture of coexistence that favours forest protection" (Article 20).

- Local community forest committees are given wide-ranging powers in relation to management of the community forest (Article 31). The committee sets down the local regulatory framework for forest management including the demarcation of conservation and gathering areas and rules for the conservation and use of animals and vegetation. They are able to expel non-compliers from the membership of the community forest; they can require compensation; take legal action; refer matters to the public prosecutors; and are given wide-ranging local policing powers.

- Locally developed plans for the operation of the community forest must be submitted to the provincial committee at the time of application. These plans must set out "protection" and "use" areas within the community forest (Article 20).

\section{Who is included under the community forest umbrella?}

The focus of the proposed community forest legislation is the "local community" with only members of such "communities" permitted to apply for the establishment of a community forest. In Article 4 of the people's version "local community" is defined as "the group of people that live together as a society in the same area and pass down their culture together." A commentary on this definition suggests communities so defined "must be original local communities" (Anon, nd) and this terminology is actually adopted in some provisions of the version passed by the House of Representatives. Applications to establish community forests in forest conservation areas must also demonstrate a history of sustainable forest management and a "culture of coexistence that favours forest protection" (Article 20). This emphasis on originality and sustainability is consistent with Article 46 of the new Thai constitution which grants "rights in the management, maintenance, care and use of benefits from natural resources and the environment in a balanced and sustainable manner" to "persons so assembling as to be an original local community." It is also consistent with the broader emphasis in the community forest literature on the correspondence between sustainable resource use and communities characterised by strong kinship ties, cultural continuity, vibrant ritual activity and, of course, a non-commercial orientation.

\footnotetext{
${ }^{2}$ The version passed by the House of Representatives requires in that there be at least 50 native residents aged over 18 involved in the establishment of the community forest (Article 18).
} 
One of the primary justifications for this particular approach to community is that it will prevent external investors gaining a stake in local resource management. The commentary on the people's version of the bill referred to above suggests that the emphasis on membership of original local communities will mean that "others will not be able to sneak in and manage the community forests" (Anon, nd). This is contrasted with the more general definitions proposed in some government versions under which, the commentary asserts, virtually anyone claiming local residency could make application for community forests including "capitalists who have resorts or land" close to forested areas. These more general provisions, it is argued, may even allow investors to set up "community forests" that are, in fact, commercially-oriented tree plantations.

These concerns are understandable - and they are widely voiced in the community forest literature - but the distinction between legitimate "insiders" and illegitimate "outsiders" that underlines the argument is often rather blurred on the ground. The test of "originality" and cultural continuity appears particularly problematic in frontier areas - and there are numerous local frontiers in the uplands of northern Thailandwhere histories of settlement are relatively short and where local residents often have diverse origins (Hirsch, 1997). Just to give one example, Del Castillo's (1990: 39) study of the fermented tea (miang) producing village of Kui Tuai indicates that resident households came from seven different districts in Chiang Mai province with eight households arriving between 1980 and 1988, a further six between 1971 and 1980 and eight between 1961 and 1970. By any definition it is difficult to see how this group of villagers - for whom forest resources are undoubtedly crucial - could validly present themselves as an original local community eligible to apply for a community forest. Indeed, Anan (2000: 75) writes of such recently settled villages as not being old enough "to make their members have a sense of belonging and to create a stable land use tradition" clearly putting them outside the definitions proposed by the community forest movement.

Even in non-frontier areas of seemingly long-term settlement, images of demographic homogeneity and cultural continuity may be misleading and the task of identifying members of the "genuine local community" (Anon, nd) may be difficult and, ultimately, somewhat arbitrary. For example, the survey undertaken in Mae Chaem district, referred to above, found that 26 percent of household heads were born outside their current village, with most entering the village as a result of marriage. Given that the self-nominated household heads were predominantly male, the survey did not capture the significant number of in-marrying women, nor, given its agricultural focus, did it capture in-migrating shop-keepers, other local business operators or government employees who may also have legitimate stakes in local resource management. The survey also identified significant numbers of "residents" living outside the village for varying periods of time to pursue education and nonagricultural employment and to meet geographically dispersed kinship obligations. How many of these "inside-outsiders" may be excluded when lists of "original" or "genuine" local community membership are being drawn up (and bear in mind that it is proposed that as few as 10 representatives of a local community can make application for a community forest)? Most may applaud the exclusion of the resortowning capitalist but what about the woman who returns from a number of years of urban employment who seeks to use her modest savings to re-establish a position in local agriculture? And what about the in-marrying husband who finds himself socially 
isolated after a bitter divorce? Or the schoolteacher or local bank clerk who has bought up a hectare or so of fruit orchard? Or even the shopkeeper who rents out her agricultural fields to tenants from a neighbouring village and has a small teak plantation that she plans to sell to pay for her daughter's education? How many people with a legitimate interest in local resource management may be excluded by inappropriately narrow tests of sociality, cultural transmission or originality?

\section{Are agricultural lands included?}

What is the status of agricultural land within the proposed community forest framework? This is a crucially important question given that, as noted above, there are large areas of agricultural land located within "forest reserve" areas on which tenure rights are ill defined and uncertain. What will the proposed community forest legislation do to enhance the security of farmers working these ambiguous lands? What sort of land use does the community forest bill seek to endorse and facilitate?

It is difficult to provide clear answers to these questions. Some definitional investigation is necessary. To begin with, "community forest" is defined an area of "forest" over which the establishment of a community forest has been approved. "Forest" is defined in the people's version as "land that is not yet legally occupied or cultivated by any person." The wording in the version passed by the House of Representatives - "land that no one has obtained under the land code"-is somewhat narrower though the intention appears to be similar. The emphasis on the lack of legal occupation in both cases is important as it suggests that the bill may legitimise the currently illegal cultivation of land classified as forest. But this does not appear to be the case. Surprisingly, given the fundamental and oft-repeated claim that people and forests can and do co-exist - the basic claim that has underlain the community forest movement - at no point does the proposed legislation state that agriculture is a legitimate activity within community forest boundaries. Indeed Article 34 of the people's version specifically forbids anyone to "control land, farm, live in, build, burn, clear, lop, gather or do anything else that would cause destruction to the forest in the community forest area." Some exceptions are listed, but these relate to the administration of the community forest (Article 34.1 to 34.3), collection and harvesting of forest products under local regulation (Article 34.4 and 34.5) and tree planting (Article 34.6). The legislation does make provision for "zones for use" but the Thai term used here (kaan chay sooy) usually implies, in discussions of forest management, collection of forest products rather than agricultural activity (Anan, 1999: 37; NDF, 2000a: 12; Pritsana and Chanthawong, 1998: 19).

This interpretation would suggest that the proposed community forest legislation would offer no enhanced security for farmers whose agricultural lands lie in the ambiguous zones of forest reserves. The formal status of their fields would not change and the mismatch between formal land classification and actual land use would be unresolved. Despite all the claims about community forest legislation providing a basis for sustainable and secure upland livelihood, the central elements of this livelihood-agriculture and rights to agricultural land - have no clear place within the proposed legislative framework. It is ironic that while official versions of the bill that restrict access to forest products are vigorously condemned as amounting to a denial of the livelihoods of upland villagers (Anon, nd) the fact that all versions of the bill 
are silent about agriculture has passed largely without comment. Vandergeest is one of the few that has drawn attention to this issue, arguing that "the resource rights specified in the draft Bill are so circumscribed ... that, if enforced, they would fail to address the central conflicts in [protected areas]." He suggests that the proposed bill is presented primarily as a "tool for environmental protection and development ... not for defining and protecting land rights" (1996: 266, my emphasis).

The possibility that community forest legislation may make the tenure of some farmers even more insecure must also be considered. Given that agriculture does not feature as a legitimate community forestry activity, those with agricultural plots that fall within the boundaries of legislatively endorsed community forests may face significant pressure to relocate. Already there is some evidence, anecdotal and other, that owners of upland fields in a number of villages are being "encouraged" to restrict or shift their cultivation in order to maintain the integrity and strategic promotional value of the local community forest. For example, Charal et al (2002: 11-13) write of a Hmong village in Chiang Mai province where "village land use is currently under revision:" farmers with plots in protected areas are "encouraged ... to allow the land to return to natural forest" and the protected headwater forest is extended "to include some of the agricultural fields in the upper part of the village." It is important to note such rain-fed hill-slope fields are often the primary income source for the very poorest and most marginal farmers in upland communities (Walker, 2003). Numerous writers have also reported situations where "community forestry" has been used as a tool to pressure farmers from neighbouring villages out of disputed hinterland areas, and this must be acknowledge as a key part of the "tradition" of community forest management (Anan, 2000: 66). Chusak and Deardon (1999), for example document the use of various forms of "community-based" watershed management to resist "hill tribe" encroachment in the Ban Luang area of Nan province. Locally developed "operational rules" for forest management prohibit forest clearing by "hill tribes" and the authors report that "the last village that tried to locate there was burned down by the villages, along with all the crops" (Chusak and Dearden, 1999: 680 and 679).

\section{A broader approach to land management?}

Some would argue that an interpretation that suggests that agricultural lands are excluded from the community forest framework-whether by fire or by fiat - is overly literal and narrow. A number of writers, for example, explicitly reject the technical and "Western" view that community forests are restricted to conservation areas and village use-forests and, by contrast, include agricultural land and settlement areas under the community forest umbrella (for example, NDF, 1999: 76, 108, 115; Pritsana and Chanthawong, 1998: 67-68). According to this view, agricultural lands are seen as being a particularly important component of the community forest domain given their contribution to local systems of ecological diversity. While the specific provisions of the legislation may seem narrow, it is argued that recognition of local community forestry rights will provide a basis for negotiation of the entire package of land use in forest reserve areas. Anan and Mingsarn (1995), for example, argue that the state should recognise traditional systems of land management and allocation in exchange for a commitment to forest protection. Similarly Thomas et al. (2003: 37) suggest that community forest legislation may provide "the legal basis for a process that could recognize local land use zoning agreements and landscape mosaic 
agroforestry management practices." Even some areas of government appear sympathetic to this view with a Royal Forest Department (1998: 7) publication, for example, suggesting that community forests could be a basis for "both forest and agriculture to exist appropriately and in a well blended manner ... in the one area."

All this appears rather promising, but to the extent that agricultural lands are included within this broader approach to community forestry they are incorporated within a framework that privileges communal forms of property. ${ }^{3}$ Community forestry s seen as countering a long trend in resource regulation that has privileged private property on the one hand and state property on the other. Neither of these "Western" forms of property is seen as being appropriate given the particular circumstances of resource management in the forested uplands of Thailand (Chusak, 1999). It is often argued that the upland political economy was characterised by communal land management prior to the disruptive intrusion of the state and the market. While the erosion of communal arrangements in recent decades is acknowledged it is argued that they continue to form part of the repertoire of local knowledge and that legislative recognition will enhance the ability of local communities to pursue sustainable resource management (Atjara, 1999: 70-71).

But how realistic is this emphasis on communal tenure in relation to agricultural land? While, historically, there may well have been forms of common property that governed some areas of agricultural land, there are also longstanding practices in upland areas that grant de-facto private ownership to the person who clears forest land for agricultural use (Ammar et al., 1991: 37). For example, in relation to the Hmong of Mae To, Geddes (1976: 149) noted that the first person clearing agricultural land "gained complete rights of use and disposal" and that cleared land "may pass to new occupiers by loan, by mortgage, by gift, or by purchase" (see also Lee, 1981: 104). Kwanchewan also suggests that the rights of first clearers are also acknowledged in relation to upland plots in some Karen communities (Kwanchewan, 2539: 55). Individual land rights are even more clearly evident in the popular settlement areas along upland streams where the construction, maintenance and cultivation of paddy fields have long been predominantly household enterprises. Individual ownership of paddy fields is well documented in northern Thai (Tanabe, 1994: 17), Karen (Anan, 2000; Hamilton, 1976: 61) and Hmong communities (Lee, 1981: 104). Of course, paddy farming often relies on communal forms of labour recruitment and water management but these forms of resource mobilisation-for household productionshould not be confused with communal ownership of land. This local recognition of de facto individual tenure is reflected in the fact that informal land markets are already active in upland areas despite that lack of legislative recognition. ${ }^{4}$

Where there does appear to be a more communal approach is in relation to agricultural lands left fallow or abandoned. Writing of the Hmong, Geddes (1976: 149) suggests that "rights to land evaporate with its disuse" and that others are

\footnotetext{
${ }^{3}$ For example, Anan (1997: 214; 1999: 41; 2000: 13-17, 73); Apichai (1997: 77-78); Northern Development Foundation (2000b: 7, 35-40, 44-46); Pheemsak (2000b: 20); and Pinkaew (1996: 126128; 1999a: 27).

${ }^{4}$ See, for example, Ammar et al. (1991: 28); Benchaphun (1994: 6); Chan (1994: 54); Geddes (1976: 148-149); and Panayotou and Parasuk (1990: 64-65).
} 
relatively free to re-clear and cultivate the land. ${ }^{5}$ In many Karen farming systems communal ownership and management of fallow lands has been well documented, with farmers often allocated only temporary use rights to clear and cultivate (Hinton, 1979: 82; van Eckert et al., 1992: 12). Under such systems-where land "cycles" between individually managed cultivation and communally managed fallowgranting permanent private title would clearly be inappropriate and a more "communal" approach, that recognises temporary use rights, is likely to be more effective. But this must be set against trends over the past few decades in relation to the intensification of cultivation. Among Hmong farmers it is now clear that most cultivation is undertaken on a permanent basis with "fallow" limited to only short periods of non-cultivation. Widespread investment in land improvement, water supply systems, green-houses, soil conservation and fruit trees has meant that previous practices of abandonment and re-cultivation by a new farmer are now virtually nonexistent. In Karen villages, though the level of intensification has been somewhat less marked, there has also been a strong trend to permanent cultivation. Kwanchewan, for example, reports that upland fields in the Karen village of Mae Lu are "continuously cultivated for an average of 5.4 years, while fallowed fields were left uncultivated for an average of only 2.8 years" (Kwanchewan, 2539: Abstract). She notes that "upland fields, upland fallow and paddy are the property of the household, or to be specific it is the mother and the father ... who are the owners" (Kwanchewan, 2539: 55, my emphasis).

This very brief review of historical and current tenure practices suggests that considerable caution should be exercised in adopting communal title as a template for management of agricultural lands in upland areas. It may be appropriate in some cases, particularly where long fallow systems mean that agricultural lands are characterised by temporary use rights that "evaporate" when cultivation is replaced by forest. But this rather arboreal version of agriculture is now relatively uncommon and becoming increasingly so in a context of upland intensification and commercialisation. While "holistic" approaches to land management are desirable, this should not amount to an uncritical extension of property arrangements that may be appropriate in the case of fallow lands or forest to the very different context of permanently cultivated agricultural land. While an arboreal perspective of agriculture may make this extension seem logical and even desirable, there are a number of key issues that highlight how problematic a "forest-based" approach to agricultural tenure may be.

First, communal forms of title will prevent farmers from using their land as security for loans. The limitations placed on farmers' capacity to mobilise capital for use on "perfectly good agricultural lands" in forest reserve areas has been identified as one of the primary negative impacts of current forest policy (Ammar et al., 1991: 12, 28; Panayotou and Parasuk, 1990: 64-65; Warr, 1993: 75). In upland areas where more formal individual title is available, use of land as credit collateral has been a key factor in facilitating increased land productivity, largely through investment in cash crops such as soybeans, garlic, vegetables and flowers but also through investment in improved soil and water management measures. Of course, there are many who see

\footnotetext{
${ }^{5}$ Lee notes that land left fallow can be used by other farmers "but always provided the first user relinquishes his claim, otherwise permission will have to be sought and a small fee may even have to be paid" (Lee, 1981: 104, my emphasis).
} 
the proliferation of agricultural debt as regrettable and as undermining local selfsufficiency but it would seem desirable for farmers themselves to make this assessment rather than having a substantial group of them denied the option by the imposition of communal tenure on privately held lands. It is important to note that farmers with formal individual title are able to obtain credit from official lending sources (the Bank of Agriculture and Cooperatives in particular) where interest rates are relatively low and foreclosure action is relatively infrequent. Those who lack appropriate title are forced into more informal credit markets (Ammar et al., 1990: 280) where the costs and risks are substantially higher (Anan, 2000: 176-177).

Second, it seems unlikely that farmers would welcome the regulatory empowerment of village committees in relation to agricultural land use. As noted above, a requirement under the proposed legislation is that communities seeking to establish community forests demonstrate a "culture of life that is consistent with care of the forest." How might the action of community forest committees in monitoring and enforcing such a "culture" impact on household autonomy and adaptability in a context of agricultural intensification and widespread commodity production? Who will be the local arbiter of consistency between agricultural practices and forest health? The broader community forest literature makes it clear that such a forest friendly culture of life is based on low chemical input, low technology, and an emphasis on subsistence production while production of cash crops is regularly targeted as one of the primary causes of forest destruction. (NDF, 2000a, 2000b; Pheemsak, 2000a: 36; Pratuang, 1997: 118; Somsak, 2000: 14). What might the impact be of the implementation of this community forest consensus on local attempts to intensify and diversify agricultural production?

Third, it seems equally doubtful that many farmers would accept the proposals for allocation and reallocation of agricultural land that are implicit in many discussions of communal land management. In particular, the currently popular approach of participatory land use planning - that the proposed community forest bill is seen as facilitating - appears to be based on the premise that "communities" should manage the allocation of land between various forest and agricultural uses. Garrity, (1998) for example, writes of a case where committees were established to develop "communityenforced land use rules" and to categorise the landscape into a "mosaic of areas of various types of land use." The identified agricultural areas are "managed by individual households ... subject to necessary conditions imposed by the community" (my emphasis). The case study is illustrated with a "before-and-after" map illustrating the planned consolidation of once dispersed upland fields (and their exclusion from the newly demarcated community forest), the extension of paddy areas and the establishment of orchards. What remains unanswered in these sorts of case studies is how such systems of community based land re-allocation impact on the rights of individual landholders. How are farmers encouraged to relocate their upland fields? Whose paddy fringe gardens are absorbed by planned paddy expansion? Whose lands are put of production in the short term to achieve long-term returns from fruit orchards? In brief, how are highly complex and decentralised processes of landscape evolution compressed into the framework of committee-based landscape planning?

While acknowledging these problematic aspects of communal approaches to agricultural land management, some would argue that the alternative of granting individual forms of title is simply unacceptable given the risks of outside investors 
gaining access to land. Community forest advocates condemn previous systems of forest land allocation that granted individual title on the basis that they have destroyed community-level institutions and undermined traditional values opening the way for commercialisation, corrupt dealings and investor intrusion. ${ }^{6}$ In some cases, upland villagers are said to be uninterested in individual title based on the view that "if they have no tenure documents the capitalists will not be interested." (Anan and Mingsarn, 1995: 302) and one advocate of the proposed legislation specifically states that "villagers do not want land rights" (Somsak, 2000: 5). Recently, when Prime Minister Taksin proposed that limited title granted in land reform areas be upgraded to full title - with the possibility of revoking the forest reserve status of some areas of agricultural land - there was vigorous opposition from some of the key players in the community forest campaign. Their opposition was based on the views that full tenure would allow farmers to use their land as collateral, burden themselves with "heavy debts" and squander the borrowed money. The end result would be that "their land would be snapped up by businessmen" (Post Reporters 2002).

These are important considerations, but they raise further issues that, I suggest, warrant ongoing discussion. What is being argued is that a sub-group of the nations' farmers, chosen somewhat arbitrarily on the basis that their lands happen to fall within state-imposed forest reserve, should not receive the tenure rights that predominate in other areas of the country. Despite the considerable emphasis placed on the resource management capabilities of these upland farmers it is suggested that they should be protected from the risks of resource transaction by the non-provision of individual land rights in relation to their agricultural fields. It seems that not only are these farmers expected to be responsible for environmental conservation (pursuing lifestyles consistent with protection of the forest) but they are also to be responsible for a form of socio-economic conservation whereby they are denied the opportunity to participate equally in the broader economy. It is certainly possible that some farmers may agree with this approach and may wish to pursue recognition of their "communal" land rights under the broad framework of community forestry. Some may see internal community recognition of their individual rights as being more important that formal state recognition. But these should be seen as options. The community forestry act may provide for these options (but remember that nowhere in the legislation is agricultural activity actually permitted) but the hostility to various forms of individual title appear to rule out recognition of rights that appear consistent with longstanding trends in upland land management in the region.

\section{Conclusion}

Community forestry in this context is an issue of contested resource tenure between local people and the state. (Hirsch, 1997: 16)

The community forest movement in northern Thailand represents a challenge to the denial of resource rights of farmers located in forested upland areas. At present the denial of farmers' rights is potently expressed in the fact that officially declared forest conservation areas contain numerous communities and vast areas of "illegal" agricultural land. In asserting the rights of these farmers, and in countering illconceived plans for relocation of upland villages, the community forest movement has

\footnotetext{
${ }^{6}$ For example, Anan (1999: 42-43); Pratuang (1997: 134); and Thomas et al. (2003: 36).
} 
argued that coexistence of people and forest is possible due to the intimate relationship between rural livelihoods and forest ecosystems. Widely promoted images of communities leading simple, non-commercial lifestyles, practicing forms of forest-friendly cultivation, implementing indigenous forms of watershed management and carefully managing a diverse range of forest products help to open up "cultural spaces" (Anan 2000: 202-220) in which it can be asserted that local management of resources is the key to ensuring livelihood security and resource sustainability. The proposed community forest legislation encapsulates this desire to transfer resource management rights to local forest-dwelling communities.

My basic argument in this paper is that the assertion of the intimacy between upland livelihoods and forests has resulted in what I have called an arborealised perspective of upland agriculture. One of the key effects of this arborealised perspective is that the particular characteristics of contemporary upland agriculture have become hidden in the normative and descriptive thicket of forest friendly discourse. As upland farmers have blended into the trees, giving local communities a greater role in forest management has come to be seen as the best response to state denial of livelihood rights. The result is proposed legislation that seeks to give local committees the right to manage community forests in areas currently claimed by the state as forest reserves. However, the reforms appear to apply only to people living in a state of community that conforms to the forest-friendly imagery of homogeneity, cultural continuity and non-commercial orientation. Moreover, and this is the key limitation, a literal reading of the legislation suggests that agriculture is not permitted in areas managed by these community forest committees. A considerably more generous reading of the legislation and associated literature suggests that agriculture may be permitted under a broader process of land use reform facilitated by the legislation but this process is one that gives primary emphasis to communal forms of land ownership and management. Overall, the community forest legislation appears somewhat disconnected from the upland realities of frontier settlement, demographic fluidity, widespread commodity production and predominantly individual management of agricultural land.

I should emphasise that in making this critique I do not wish to dismiss the achievements of the community forest movement. In an environment where some upland communities are under real threat of relocation it is surely appropriate to use whatever discursive strategies may be required to relieve their position. As Li (2002) has noted the "environmental hook" has proven to be internationally effective in promoting and defending the rights of minority peoples under pressure from state regulation and extractive capitalism. In northern Thailand, there is little doubt that vigorous promotion of the imagery of forest-friendly upland community has contributed to a softening of the official emphasis on relocation and a greater willingness to explore options embracing "local knowledge," agro-forestry, decentralised management and state-community networks. There is also little doubt that the symbolism and practice of community forestry has been taken up by some upland residents to counter negative, and racist, stereotypes. The community forest campaign has made an important contribution to establishing a legitimate place for upland communities in contested northern Thai landscapes.

Nevertheless, I would suggest that there are risks in this campaign, especially when relatively diffuse symbols of forest coexistence come to be fixed in legislative form. 
There is, I argue, a strong sense in which the assertion of the rights of upland farmers has become overly constrained by the (counter-)discursive form that the assertion has taken. The legitimacy of upland occupation proposed by the community forest campaign appears to have limited relevance to farmers involved in complex and dynamic processes of commodity production and agricultural intensification. The nature of this limitation has been highlighted in recent commentary prompted by the Senate's rejection of key provisions of the proposed bill. Some senators expressed fear that the proposed bill would allow upland farmers to "convert the fertile forest to cabbage and other cash crops" and "claim their cabbage plantations as community forest" (Pennapa, 2002). Seemingly startled by this public "outing" of the reality of upland commercialism the advocates of human-forest coexistence retreated to the safe discursive ground of conservation. The Northern Farmers' Network responded that the bill "aims to make us responsible for protecting nature in our communities. It doesn't allow a person or group of people to live in, or to make a living in the forest" (Supara, 2002, my emphasis). And a key academic advocate of community forestry argued that the bill "gave local communities the right to manage the forests, not to occupy forest land" (Niti quoted in Kultida, 2002, my emphasis).

The irony here is that advocates for community forestry end up promoting the position that the campaign set out to oppose: that agricultural presence and forest conservation are incompatible. The legislation is now defended on the basis that it will not allow agricultural occupation of forest land. This somewhat surprising outcome is, I suggest, the result of a campaign that is based on an arborealised view of agriculture that is simply inconsistent with contemporary upland realities. Once these realities are entered into the debate - and cabbages are a potent symbol of agricultural change and non-forest oriented commercialisation - the arborealised basis of the claim to legitimate residency is simply cut away and the proponents of upland rights have little alternative but join the state in excluding agriculture from the domain of forest conservation. As Conklin and Graham have argued in relation to the ecopolitics of the Amazon (Conklin and Graham, 1995: 705-706) "generic representations, no matter how sympathetic, inevitably turn into liabilities when the disjunctures between external images and indigenous realities become manifest."

This community forest cul-de-sac highlights the potential benefits of some more radical advocacy of the rights of upland farmers. Alternative arguments mounted to secure the rights of farmers whose agricultural lands have been classified as forest reserve may, for example, point to the growing body of evidence that there is no simple relationship between commercialism and forest destruction and that relatively market oriented villages may be in the best position to manage and protect neighbouring forested areas (Anan, 1999: 39; 2000: 70, 196-197; Chusak and Dearden, 1999; Kessler, 1998; Sopin et al., 1990). These arguments could also point to evidence that upland agricultural intensification can take pressure off forest by enhancing the productivity of existing cultivation (Kanok et al., 1994). Similarly, rather than portraying upland farmers as guardians of environmental services, hydrological evidence could be deployed to refute the widely voiced claims that past forest clearing has compromised water supply (Walker 2003). And, at a broader level, rather than being stereotyped as a consumptive assault on forest ecosystems, upland cash cropping could be portrayed as one important component of the

\footnotetext{
${ }^{7}$ No, the response was that "commercial agriculture will not be permitted in conservation areas".
} 
development of Thailand's agricultural sector, linking upland villages with regional, national and even international markets. Of course, there is no reason why community forestry cannot be part of this broader package of advocacy, but to the extent to which it is based on, and vigorously promotes, a narrowly defined arboreal version of agriculture it will continue to exclude these more radical possibilities.

\section{Bibliography}

Ammar Siamwalla, Nipon Poapongsakorn, Prayong Nettayarak, and Yuavares Tubpun. 1990. 'The Thai rural credit systems: public subsidies, private information, and segmented markets', The World Bank Economic Review 4 (3): 271-295.

Ammar Siamwalla, Suthad Setboonsarng, and Direk Patamasiriwat. (1991) Thai agriculture: resources, institutions and policies. Bangkok: Thailand Development Research Institute Foundation.

Anan, Ganjanapan. 1997. 'The politics of environment in northern Thialand: ethnicity and highland development programs'. In P. Hirsch (eds) Seeing forests for trees: environment and environmentalism in Thailand, pp. 202-222. Chiangmai: Silkworm Books.

1999. 'Will the community forest law strengthen management of community forests?' (in Thai). In Northern Development Foundation (ed) 3 decades of community forestry: in the midst of confusion of Thai society, pp. 35-57. Chiang Mai: Northern Development Foundation.

- 2000. Local control of land and forest: cultural dimensions of resource management in northern Thailand. Chiang Mai: Regional Center for Social Science and Sustainable Development, Faculty of Social Sciences, Chiang Mai University.

Anan Ganjanapan, and Mingsarn Khawsaard. 1995 The development of forest clearing for agriculture in the upper northern region (in Thai).

Anon. nd. Draft community forest laws: differences between the people's version and the government versions (In Thai). Manuscript.

Apichai Puntasen. 1997. 'The Tambon Council and community forest managment'. In P. Hirsch (eds) Seeing forests for trees: environment and environmentalism in Thailand, pp. 72-88. Chiang Mai: Silkworm Books.

Apinyaa Tanthawiwong. 2001. 'Summary of the important content from the 6 case studies'. In Princess Maha Ckhakri Sirindhorn Anthropology Centre (ed) The cultural dimension in the era of the sufficiency economy (in Thai), pp. 19-70. Bangkok: Princess Maha Ckhakri Sirindhorn Anthropology Centre.

Atjara Yudtithaam. 1999. 'From forest law and policy to the new constitution: claiming community rights in resource management' (in Thai). In Northern Development Foundation (ed) 3 decades of community forestry: in the midst of confusion of Thai society, pp. 59-75. Chiang Mai. 
Benchaphun, Shinawatra. 1994. Property rights, institutions, and access to resources: impacts on sustainable intensification in northern Thailand. Chiang Mai: Multiple Cropping Centre.

Chakrit Ridmontri. 1998. New forestry chief rules out man and nature coexistence. Bangkok Post, April 15, 1998.

Chan, Man-Kwun. 1994. Tree resources in northern Thailand: local stakeholders and national policy. An interim report of the research programme on "Tree Resources and Environmental Policy: Stakeholders and Trade-offs": Natural Resources Institute, Overseas Development Administration.

Charal Thong-Ngam, Thamanoon Arretham, Prasong Kaewpha, Songsak Thepsarn, Narit Yimyam, Chavalit Korsamphan, and Kanok Rerkasem. 2002. 'Scaling up a PLEC demonstration site for the national pilot programme: a case example of a hmong njua village in northern Thailand', PLEC News and Views 19: 7-16.

Chusak Wittayapak. 1999 'Obstacles to the community forest bill: a problem of lack of ideas or a lack of institutional imagination. In Northern Development Foundation (ed) 3 decades of community forestry: in the midst of confusion of Thai society, pp. 77-99. Chiang Mai: Northern Development Foundation.

. 1999. 'The community culture revisited: community as a political space for struggles over natural resources and cultural meaning'. Paper presented at 7th International Conference on Thai Studies, 4-8 July 1999, Amsterdam.

Chusak Wittayapak, and Philip Dearden. 1999. 'Decision-making arrangements in community-based watershed management in northern Thailand', Society and Natural Resources 12: 673-691.

Conklin, Beth A, and Laura R Graham. 1995. 'The shifting middle ground: Amazonian Indians and eco-politics', American Anthropologist 97 (4): 695710.

Del Castillo, Donato Romulo C. 1990. Analysis on the sustainability of a forest-tea production system: a case study of Ban Kui Tuai, Tambon Pa Pae, Amphoe Mae Taeng, Changwat Chiang Mai, Agricultural Systems, Chiang Mai University, Chiang Mai.

Doornbos, Martin, Ashwani Saith, and Ben White. 2000. 'Forest lives and struggles: an introduction', Development and Change 31: 1-10.

Ekawit na Thalaang. 2001. Local wisdom of Lanna (in Thai). Bangkok: Aamrin.

Forsyth, Tim. 1999. 'Historical evidence for watershed degradation: how important is agriculture?' paper presented at Environmental Services and Land Use Change: Bridging the Gap Between Policy and Research in Southeast Asia, Chiang Mai.

Garrity, Dennis P. 1998. 'Participatory approaches to catchment management: some experiences to build upon'. Paper presented at Managing Soil Erosion Consortium Assembly, Hanoi.

Geddes, William Robert. 1976 Migrants of the mountains: the cultural ecology of the Blue Miao (Hmong Njua) of Thailand. Oxford: Clarendon Press. 
Hamilton, James W. 1976 Pwo Karen: at the edge of mountain and plain. St Paul: West Publishing Company.

Hansen, Peter K. 2001. 'The forest as a resource for agriculture in northern Thailand'. In E. Poulsen, F. Skov, L. Sureeratna, T. Sornprach, H. Borgtoft and O. Hoiris (eds) Forest in culture - culture in forest: perspectives from northern Thailand, pp. 147-162. Tjele, Denmark: Research Centres on Forest and People in Thailand, Danish Institute of Agricultural Sciences.

Hinton, Peter. 1979. 'The Karen, millennialism, and the politics of accommodation to lowland states'. In C. F. Keyes (ed) Ethnic adaption and identity: the Karen on the Thai frontier with Burma, pp. 81-94. Philadelphia: Institute for the Study of Human Issues.

Hirsch, Philip. 1997. 'Community forestry revisited: messages from the periphery'. Paper presented at Community Forestry at a Crossroads: Reflections and Future Directions in the Development of Community Forestry. (RECOFTC Report No. 16), 17-19 July 1997, Bangkok.

Kannika Phromsao, and Bencha Silarak. 1999. The seven layer forest (in Thai). Bangkok: Munnithi Phumpanya.

Kanok, Rerkasem, and Benjavan Rerkasem. 1994. Shifting cultivation in Thailand: its current situation and dynamics in the context of highland development. London: International Institute for Environment and Development.

Kanok, Rerkasem, Benjavan Rerkasem, Mingsarn Kaosa-ard, Chaiwat Roongruangsee, Sitanon Jesdapipat, Benchaphun Shinawatra, and Pornpen Wijukprasert. (1994) Assessment of sustainable highland agricultural systems. Bangkok: Thailand Development Research Institute Foundation.

Kessler, Christl. 1998. Community forestry in Thailand. The World Bank/WBI 1998. Available from http://srdis.ciesin.org/cases/thailand-002.html. Viewed 24 October 2002

Kultida Samabuddhi. 2002. Academic slams senators over ban. Bangkok Post, 29 March 2002.

Kwanchewan Buadaeng. 1996. Changing lifestyles of a Karen community (in Thai). Chiang Mai: Social Research Institute, Chiang Mai University.

Lee, Gar Yia. 1981. The effects of development measures on the socio-economy of the white Hmong. Thesis for Doctor of Philosophy, Department of Anthropology, University of Sydney, Sydney.

Li, Tani Murray. 2002. 'Engaging simplifications: community-based resource management, local processes and state agendas in upland Southeast Asia', World Development 30 (2): 265-283.

NDF (Northern Development Foundation). 1999. 'Study of biodiversity and ecology in community forests in the upper-northern region' (in Thai). In Krom Songsoem Khunnaphab Singwaetlom (ed) Local wisdom and the management of natural resources, pp. 53-174. Bangkok: Krom Songsoem Khunnaphab Singwaetlom.

2000a. Villager's networks: participatory management of watershed resources (in Thai). Chiang Mai: Northern Development Foundation. 
- 2000b. Lines of thinking and directions: participatory management of watershed resources (in Thai). Chiang Mai: Northern Development Foundation.

Nithi Ieosriwong. 2001. 'Cultural dimension in the era of the self sufficiency economy: meaning and importance' (in Thai). In Princess Maha Chakri Sirindhorn Anthropology Centre (ed) Cultural dimension in the era of the self sufficiency economy, pp. 3-17. Bangkok: Princess Maha Chakri Sirindhorn Anthropology Centre.

Olsen, Carsten S, Catherine Traynor, Vipak Jintana, Chusee Trisonthi, and Intawat Burikam. 2001. 'The forest as a resource for non-timber produce'. In E. Poulsen, F. Skov, S. Lakanavichian, S. Thanisawanyangkura, H. Borgtoft and O. Hoiris (eds) Forest in culture - culture in forest: perspectives from northern Thailand, pp. 131-45. Tjele, Denmark: Research Centre on Forest and People in Thailand, Danish Institute of Agricultural Sciences.

Panayotou, Theodore, and Chartchai Parasuk. 1990. Land and forest: projecting demand and managing encroachment. Bangkok: Thailand Development Research Institute.

Pennapa Hongthong. 2002. Forest dewllers to remain in limbo. The Nation, 27 March 2002.

Pheemsak Makaraphirom. 2000a. 'Involvement of people in forest management: framework, limitations and options' (in Thai).' In Asia Pacific Forestry Training Centre (ed) Community forestry, pp. 27-48. Bangkok: Kasetsart University.

2000b. 'Is the community forest appropriate or not: how should we consider it?' (in Thai). In Asia Pacific Forestry Training Centre (eds) Community forestry, pp. 17-25. Bangkok: Kasetsart University.

Phrek Gypmantasiri, Suporn Amaruekachoke, and Panomsak Promburom. 1994. Sustainable agriculture technology development for highland area of northern Thailand. Chiang Mai: Multiple Cropping Centre, Faculty of Agriculture, Chiang Mai University.

Pinkaew Laungaramsri. 1996. Local ecological wisdom: case study of the Karen in Thung Yai Naresuan forest (in Thai). Bangkok: Khrongkan Funfu Chiwit lae Tammachat.

. 1999a. 'The communicy forest movement and the challenge to the Thai state's forest management' (in Thai). In Northern Development Foundation (ed) 3 decades of community forestry: in the midst of confusion of Thai society, pp. 15-33. Chiang Mai.

- 1999b. 'Rai, rai lu'an loy, rai mun wian and the politics of "shifting cultivation", Watershed 5 (1): 39-46.

Post Reporters. 2002. 'PM's title deeds proposal panned: another economic bubble in the making'. Bangkok Post, 3 December 2002.

Pratuang Narintarangkul Na Ayuthaya. 1997. 'Community forestry and watershed networks in northern Thailand'. In P. Hirsch (ed) Seeing forests for trees: environment and environmentalism in Thailand, pp. 116-46. Chiang Mai: Silkworm Books. 
Prawase Wasi. 1997. 'Community forestry: the great integrative force'. Paper presented at Community Forestry at a Crossroads: Reflections and Future Directions in the Development of Community Forestry (RECOFTC Report No. 16). 17-19 July 1997, at Bangkok.

Pritsana Phromma, and Montri Chanthawong. 1998. Local communities and management of biodiversity (in Thai). Chiang Mai: Project for the Development of Northern Watersheds by Community Organisations.

Royal Forest Department. 1998. Community forestry (in Thai). Bangkok: Suan Pa Chum Chon, Samnak Songseem Kaan Pluuk Pa.

Sato, Jin. 2000. 'People in between: conversion and conservation of forest lands in Thailand', Development and Change 31: 155-177.

Somsak Sukhuang. 2000. 'The community forest bill: for the people who protect the forest and for sustainability' (in Thai). In Asia Pacific Forestry Training Centre (ed) Community forestry, pp. 5-16. Bangkok: Kasetsart University.

Sopin Tongpan, Theodore Panayotou, Songpol Jetanavanich, Ketty Faichampa, and Charlie Mehl. 1990. Deforestation and poverty: can commercial and social forestry break the vicious circle? Bangkok: TDRI.

Supara Janchitfah. 2002. Senators scoff at people power. Bangkok Post, 24 March 2002.

Tanabe, Shigeharu. 1994 Ecology and practical technology: peasant farming sytems in Thailand. Bangkok: White Lotus.

Thomas, David E, Pornchai Preechapanya, and Pornwilai Saipothong. 2003.'Landscape agroforestry in upper tributary watershed of northern Thailand'. Paper presented at Workshop on Knowledge Underpinning Water and Forests Policy, 30 January 2003, at Social Research Institute, Chiang Mai University.

van Eckert, Manfred, William Bourne, and Kwanchewan Buadaeng. 1992. The Karen farming systems in Huay Poo Ling: a study of the present farming systems, an assessment of constraints and recommendations for implementation. ThaiGerman Highland Development Programme.

Vandergeest, Peter. 1996. 'Property rights in protected areas: obstacles to community involvement as a solution in Thailand', Environmental Conservation 23 (3): 259-68.

Walker, Andrew. 2001. "The "Karen consensus", ethnic politics and resource-use legitimacy in northern Thailand', Asian Ethnicity 2 (2): 145-162.

. 2002. 'Forests and water in northern Thailand', Chiang Mai University Journal 1 (3): 215-244.

2003. Agricultural Transformation and the Politics of Hydrology in Northern Thailand: A Case Study of Water Supply and Demand (RMAP Working Paper Number 40). Canberra: Resource Management in Asia Pacific Program, The Australian National University.

Warner, K. (2000). 'Forestry and sustainable livelihoods', Unasylva 51 (3). Available from: http://www.fao.org/forestry/FODA/UNASYLVA/PREV-e.stm Viewed 22 October 2002. 
Warr, Peter G. 1993. 'The Thai economy'. In P. G. Warr (eds) The Thai Economy in Transition, pp. 1-80. Cambridge: Cambridge University Press. 